\title{
Allowing for Household Preferences in Emission Trading - A Contribution to the Climate Policy Debate -
}

\author{
by
}

\author{
Michael Ahlheim *)
}

and

\author{
Friedrich Schneider ${ }^{* *}$
}

\begin{abstract}
:
In the context of emission trading it seems to be taken as given that people's preferences can be ignored with respect to the whole process of fixing emission targets and allocating emission permits to polluters. With this paper we want to reopen the debate on how citizens can be involved in this process.

We try to show how citizen preferences can be included in the process of pollution control through emission trading. We propose an emission trading system where all emission permits are initially allocated to households who are then allowed to sell them in the permit market or to withhold (at least some of) them in order to reduce total pollution. This proposal tries to overcome the fundamental disadvantage of traditional permit systems which neglect consumer preferences by solely distributing emission permits to producers / polluters. In our system the property right to nature is re-allocated to the households who obtain the opportunity of reducing actual emissions according to their personal preferences by withholding a part or all of the emission permits allotted to them. Such a change in environmental policy would mark a return to the traditional principles of consumer sovereignty by involving households (at least partially) in the social abatement decision process instead of excluding them. Another advantage of admitting households to the TEP market as sellers or buyers of permits is that this increases the number of agents in the permit market and thus significantly reduces the possibilities of strategic market manipulations.
\end{abstract}

We are grateful to Ulrike Lehr and two anonymous referees for helpful comments and suggestions.

Keywords: Environmental policy, tradable emission permits, climate policy, consumer sovereignty

JEL-Class.: Q28, Q38, D18

*) Prof. Dr. Michael Ahlheim, Lehrstuhl für Volkswirtschaftslehre, insbes. Umweltökonomie, Fakultät 4, BTU Cottbus, Postfach 1013 44, D-03013 Cottbus, Telefon: \#355/69 27 74, Fax: \#3

55/ 6924 72, E-mail: ahlheim@tu-cottbus.de

**) Prof. Dr. Friedrich Schneider, Institut für Volkswirtschaftslehre, Abteilung Wirtschaftspolitik, JohannesKepler-Universität Linz, Altenberger Str. 69, A-4040 Linz-Auhof, Telefon: \#732/2468-210, Fax: \#732/2468209, E-mail: friedrich.schneider@ik.uni.linz.ac.at 


\section{Introduction}

During the last years the popularity of emission trading as an instrument of environmental policy has increased significantly. In particular, since the Climate Change Summit in Kyoto in December 1997 where several countries agreed on concrete emission reduction targets, many proposals for the implementation of an international emission trading system have been discussed among economists as well as politicians and the public at large ${ }^{1}$. It has become clear that an international system of emission trading could be useful for the regulation of "global" and uniformly dispersed greenhouse gases like carbon dioxide where the exact geographical location of the emitting plants does not matter. On a smaller scale emission trading systems can be used effectively for the regulation of pollutants with a regional impact, such as sulfur dioxide. ${ }^{2}$ Also on a national level emission trading has been acknowledged as an alternative to emission taxes. ${ }^{3}$

The basic features of most emission trading systems are the same. A central authority such as a national government or an international assembly of national government representatives fixes a quantitative overall emission target for the whole region in question (e. g. 20,000,000 t/year of $\mathrm{SO}_{2}$ ) and then a corresponding number of emission permits is printed. The most challenging task in this context is the distribution of the tradable emission permits (TEPs) to individual polluters. There are two main allocation methods which are discussed in the economic literature as well as among practicians of environmental policy: grandfathering and auctioning. Grandfathering means that the permits are distributed without charge to the polluting firms according to their past emissions. This implies that the property right to nature or to the environment is allocated to the polluters (up to the overall emission limit, of course). Auctioning of the TEPs on the other hand implies that the property right to nature lies with the government.

It is astonishing to note that household preferences are completely ignored in this process, regardless of whether the TEPs are auctioned or grandfathered. It seems that pollution control is regarded as a business between firms on the one hand and government on the other. This conflicts with the anthropocentric nature of economic theory where the justification for all sorts of policy action is to be found in people's preferences. Why should we want to reduce emissions if not for the sake of people's well-being? Therefore, it seems illogical to exclude households from the whole process of defining pollution targets and allocating emission permits. The neglect of people's preferences in practical environmental policy also contradicts the principles of economic freedom as defined by William Hutt and his idea of consumer sovereignty: "When I think of economic freedom, I think of a productive system commanded by 'consumers' sovereignty'. This is a notion which ... indicates that ultimate power to determine the use of resources which are 'scarce' ... shall be vested in the people. It implies that the goodness or success of productive effort can be judged only in the light of consumers' preferences." 4 This seems to be justification enough to search for possibilities to involve

1 For an overview over the recent discussion see e. g. Schneider / Wagner (1998).

2 A well-known example of sulfur emission trading is the allowance trading concept following the Clean Air Act Amendments of 1990 to reduce emissions contributing to acid rain (Acid Rain Program ARP) in the U. S. (cf. for details 40 Code of Federal Regulations 73and for an evaluation Tietenberg (1998a) or Harrison (1999)).

3 Cf. e. g. Tietenberg (1998b).

4 Hutt (1943, p. 215). 
households actively in the decision processes of climate policy. In this paper we propose an emission trading system where households can at least partially influence the fixing of pollution limits according to their preferences.

The paper is organized as follows: In section 2 we give a short description of customary emission trading systems based on auctioning or grandfathering. An alternative emission trading mechanism which vests households with some influence on the determination of overall pollution limits is proposed in section 3 . In section 4 we explore the psychological background which makes our system workable, and in section 5 we consider its efficiency properties. Some concluding remarks are contained in section 6 .

\section{Emission trading}

Global pollutants such as carbon dioxide can be controlled most effectively by internationally coordinated measures. A rather popular instrument often called for in this context is an international system of emission trading which was also proposed at the Climate Change Summit at Kyoto in 1997. Such a system requires that an international board of national government representatives comes to an understanding on a global emission target with respect to the pollutant in question. Then, a corresponding number of emission permits can be printed. As a second step the representatives of the national governments must agree on the mode of distribution of these permits to the different countries. On a national level governments must decide how to allocate the TEPs to the different polluters. The same task is incumbent on government for merely national TEP systems. As mentioned above there are two main classes of allocation systems for emission permits, auctioning and grandfathering, which will be briefly reviewed in the following subsections.

\section{Auctioning}

The simplest method of allocating tradable emission permits to polluting firms is to auction them. There are several different methods of auctioning TEPs which all have the same basic features in common. ${ }^{5}$ Government offers all or a major part of the newly printed TEPs in the market, and firms have to buy enough TEPs to secure their optimal scale of production (see fig. 1). A firm's choice depends on the prices in input and output markets as well as on its individual technology and, of course, on the TEP price. In the TEP market an equilibrium price will emerge which equals the different firms' marginal abatement costs. By this mechanism the marginal abatement costs will be equated over all firms so that overall abatement efficiency will prevail in the economy under consideration. This is illustrated in the following simple model.

Let us consider an economy with $\mathbf{J}$ different firms which all produce a single composite commodity. Each firm $\mathrm{j} \in\{1,2, \ldots, \mathrm{J}\}$ maximizes its profit according to its production function $\mathrm{f}^{\mathrm{j}}\left(\mathrm{y}^{\mathrm{j}}, \mathrm{e}^{\mathrm{j}}\right)$, where $\mathrm{y}^{\mathrm{j}}$ is the vector $\left[\mathrm{y}_{1}{ }^{\mathrm{j}}, \mathrm{y}_{2}{ }^{\mathrm{j}}, \ldots, \mathrm{y}_{\mathrm{M}}{ }^{\mathrm{j}}\right]$ of inputs and the scalar $e^{\mathrm{j}}$ denotes the emissions of firm $\mathrm{j}$. We postulate that $\mathrm{f}^{\mathrm{j}}$ is strictly monotonous and concave in $\mathrm{y}^{\mathrm{j}}$ and $\mathrm{e}^{\mathrm{j}}$ which implies that the use of nature $\mathrm{e}^{\mathrm{j}}$ (as a sink for emissions) is treated like a normal input. We assume substitutability between emissions $e^{j}$ and some "normal" inputs $y_{m}{ }^{j}$ which are traded in factor

5 Cf. e. g. Cramton / Kerr (1998, p. 3 ff. or 1999, p. 263 ff.), Montero (2000) or Johnstone (1999). . 
markets (e. g. an increase in some capital input like air filters can compensate for a reduction of emissions with output being constant). Firms have to buy emission permits for every emission unit so that $\mathrm{e}^{\mathrm{j}}$ equals the number of permits bought by firm $\mathrm{j}$. The firm's profit maximization problem can be described by

$$
\begin{aligned}
\max _{x^{j}, y^{j}, e^{j} \in Z^{j}}\left(p x^{j}-q y^{j}-p_{e} e^{j}\right) \quad \text { with } \quad Z^{j}=\left\{\left[x^{j}, y^{j}, e^{j}\right] \mid f^{j}\left(y^{j}, e^{j}\right) \geq x^{j}\right\} \\
\text { and } \frac{\partial f^{j}}{\partial e^{j}}>0 \quad(j \in\{1,2, \ldots, J\})
\end{aligned}
$$

where $\boldsymbol{Z}^{j}$ is the firm's production possibility set, $\mathrm{p}$ is the output price, $\mathrm{q}$ is the vector of input prices and $p_{e}$ is the price of the emission permits. If we assume perfect competition in all markets, prices are regarded as given by the firm. Solving (1) leads to the output supply function (a), the firm's vector of demand functions for market inputs (b) and to its demand function for emission permits (c):
(a) $\mathrm{x}^{\mathrm{j} *}=\mathrm{x}^{\mathrm{Sj}}\left(\mathrm{p}, \mathrm{q}, \mathrm{p}_{\mathrm{e}}\right)$
(b) $\mathrm{y}^{\mathrm{j} *}=\mathrm{y}^{\mathrm{Dj}}\left(\mathrm{p}, \mathrm{q}, \mathrm{p}_{\mathrm{e}}\right)$
(c) $\mathrm{e}^{\mathrm{j*}}=\mathrm{e}^{\mathrm{Dj}}\left(\mathrm{p}, \mathrm{q}, \mathrm{p}_{\mathrm{e}}\right)$

The sum of the individual demands for emission permits must equal the overall emission target $\overline{\mathrm{E}}$ so that the TEP market equilibrium can be described by

(3) $\sum_{j=1}^{J} e^{D j}\left(p, q, p_{e}\right)=\bar{E}$

It should be noted that from the profit maximization problem (1) we obtain the optimality conditions

(4) $\quad p_{e}=p \cdot \frac{\partial f^{j}}{\partial e^{j}}\left(y^{j^{*}}, e^{j^{*}}\right)$

$(\mathrm{j}=1,2, \ldots, \mathrm{J})$

which imply that under perfect competition the marginal abatement costs in the firms' profit maxima $\left[\mathrm{x}^{\mathrm{j}^{*}}, \mathrm{y}^{\mathrm{j}^{*}}, \mathrm{e}^{\mathrm{j}^{*}}\right]$ are the same for all firms $\mathrm{j} \in\{1,2, \ldots, \mathrm{J}\}$. Together with the input rule

$$
q=p \cdot \nabla_{y} f^{j}\left(y^{j^{*}}, e^{j^{*}}\right) \quad(j=1,2, \ldots, J)
$$

this implies that there is overall production efficiency in the economy under consideration since the marginal products of all production factors (including the input "nature") are the same for all firms. ${ }^{6}$ This is the familiar result for an economy where environmental distortions are regulated by a TEP system (or by a uniform per unit pollution tax).

6 In practice, optimality condition (4) is often not fulfilled because TEP markets are not perfect (cf. e. g. Schmalensee et al. (1998)). 


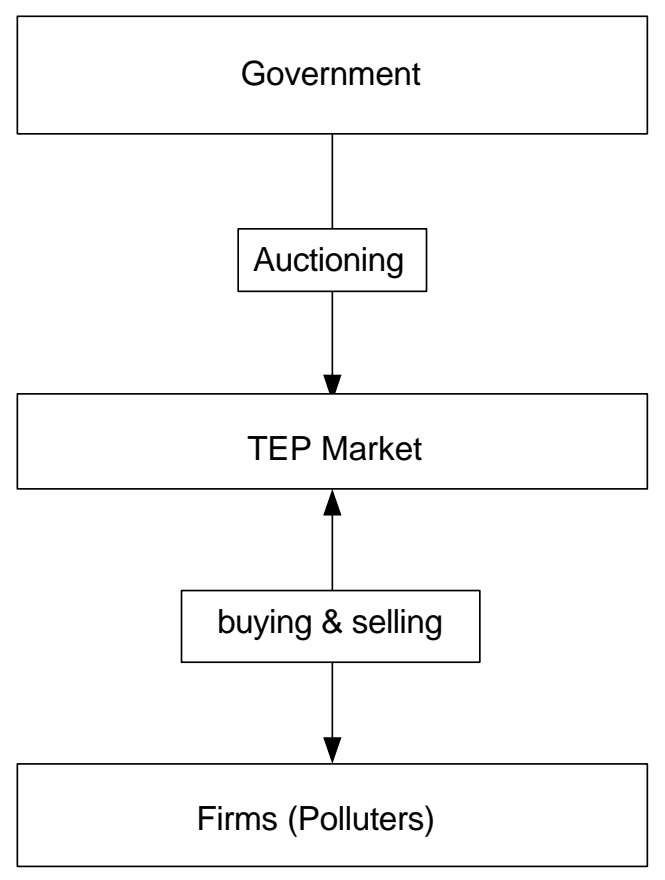

- fig. 1: Auctioning -

It is obvious that by this way of organizing a TEP system the preferences of citizens are completely excluded from the whole decision process. The property right to the environment is allocated to the government who has total control over the use of the environment in this case. It fixes the overall emission limit and it sells the "right to pollute" to the firms and, thereby, increases its revenues.

One disadvantage of the auctioning of TEPs is often seen in the fact that it extracts liquidity from firms and, therefore, means an additional financial burden to them. To avoid this problem most practical attempts to implement an emission trading system used another distribution scheme for the TEPs which is described in the following section.

\section{Grandfathering}

Grandfathering means that each polluter receives a certain quantity of free TEPs from the government where this quantity is related to his past emissions. ${ }^{7}$ This implies that no additional costs are incurred by firms from the introduction of a TEP system as long as they do not increase their emissions past their historical level. ${ }^{8}$ If polluters reduce their emissions they can sell the redundant TEPs to other firms that want to expand their activities or to newcomers who want to enter the respective commodity market. If polluters want to increase their

7 For several possibilities of designing a grandfathering system see e. g. Klaasen / Försund (1994) or Ackerman (1999).

8 Of course, this is true in the literal sense only if firms receive permits for precisely the same quantity of emissions as they produced before. If they obtain permits only in relation to their historical emissions the above statement must be modified accordingly but it still holds in a qualitative sense. 
production and, thereby, increase their emissions they have to buy additional permits in the TEP market.

The profit maximization problem of a firm $\mathrm{j}$ is changed as compared to (1) only by the fact that the firm now obtains a quantity $\overline{\mathrm{e}}^{\mathrm{j}}$ of emission permits for free. If government grandfathers all permits up to the overall emission limit $\overline{\mathrm{E}}$ it holds that

$$
\sum_{j=1}^{J} \bar{e}^{j}=\bar{E}
$$

If a firm's optimal level of emission $\mathrm{e}^{\mathrm{j} *}$ is less than $\overline{\mathrm{e}}^{\mathrm{j}}$ it can sell the difference in the TEP market at the TEP price $p_{e}$. If it needs more than $\overline{\mathrm{e}}^{\mathrm{j}}$ permits it has to buy the difference in the TEP market but it still saves emission costs to the amount of $p_{e} \bar{e}^{j}$. Therefore, grandfathering is like granting the firm a lump sum transfer of $\mathrm{p}_{\mathrm{e}} \mathrm{e}^{\mathrm{j}}$ monetary units. This becomes obvious from the firm's profit maximization problem for the grandfathering case

$$
\max _{x^{j}, y^{j}, e^{j} \in Z^{j}}\left(p x^{j}-q y^{j}+p_{e}\left(\bar{e}^{j}-e^{j}\right)\right) \quad \text { with } \quad Z^{j}=\left\{\left[x^{j}, y^{j}, e^{j}\right] \mid f^{j}\left(y^{j}, e^{j}\right) \geq x^{j}\right\} .
$$

If TEP markets are competitive each firm will, as in the case of auctioning, buy or sell emission permits until its marginal abatement costs equal the TEP price. Therefore, perfect competition on the TEP market (and, of course, in the input and output markets) leads to abatement efficiency in the sense that marginal abatement costs are equated over all firms according to (4). This means that grandfathering as well as auctioning of emission permits allows the fixed emission target $\overline{\mathrm{E}}$ to be reached at minimum overall (social) abatement costs.

The economic and ecological disadvantages of grandfathering are well known: it means a privilege for all firms that already exist at the moment when a TEP system is introduced while it results in a kind of entrance barrier for new firms that want to enter the market for the first time. Pre-existing firms do not have to pay for emissions up to their respective historical level $\overline{\mathrm{e}}^{\mathrm{j}}$ and additional costs are incurred only by additional emissions. Newcomers on the other hand have to pay for all their emissions from the start. Grandfathering is, as we saw above, equivalent to a lump-sum subsidy for the pre-existing firms. The higher the historical emission level of a firm the higher is its subsidy. This means, that firms have strong incentives to raise their emissions before the new TEP system is introduced. If only few firms participate in the TEP market they may also store the TEPs grandfathered to them even if they do not need them in order to keep new firms from entering the market. Therefore, grandfathering is counterproductive from an economic as well as an ecological point of view. 


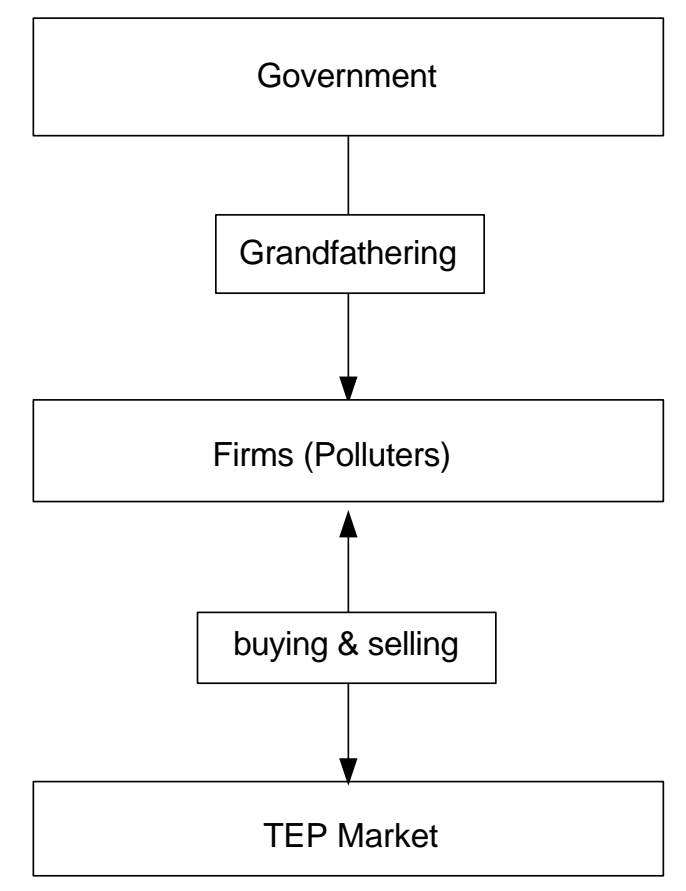

- fig. 2: Grandfathering -

As with the auctioning case grandfathering does not take into account the preferences of citizens. First, the overall emission target $\overline{\mathrm{E}}$ is fixed more or less arbitrarily by the government, and then firms can decide on the basis of their individual profit maximization considerations to what extent they abate pollution and to what extent they buy emission permits. Household preferences are entirely disregarded in this process (see fig. 2). The property right to the environment is transferred to polluting firms, i. e. at least to those firms which already exist before the TEP system is introduced. They can use the environment as a sink for their own emissions or they can sell the right to (ab)use the environment to other polluters and, thereby, increase their profits.

\section{Considering household preferences}

As was shown in the preceding section and is, of course, known from the respective literature both traditional methods of distributing emission permits to polluters, i. e. auctioning and grandfathering, are efficient in the sense that they ensure the realization of an arbitrary pollution target with minimum overall costs. This is, however, only a second-best solution since it does not guarantee the attainment of an optimal degree of pollution as would a Pigovian tax. From the discussion on the Pigovian tax it is well known that a first best optimum cannot be attained under real world conditions because the information necessary for the design of an appropriate environmental policy instrument like the Pigovian tax is not available. Nevertheless, we do not think that this can be accepted as an excuse for the total neglect of household preferences in environmental policy. As we saw above the overall 
emission target is fixed by national government alone or, in the case of an international emission trading system, by an international board of government representatives. Emission targets fixed by international political negotiations are not even approximately Pareto-optimal, as Baumol and Oates (1971) suppose, since real world politicians cannot find out people's idea of an appropriate upper limit for $\mathrm{CO}_{2}$ emissions in a single country and, typically, they are not even interested in finding it out. This means that the seeming "efficiency" of emission trading is a mere cost efficiency when the TEPs are auctioned or grandfathered.

It is hard to understand why citizens should be excluded from the property right to the environment since their well-being is the only reason for performing environmental policy at all, and they have to bear the costs of environmental protection in the form of reduced market consumption. The importance of considering people's preferences for environmental quality is broadly accepted in other policy fields. For example, it has become quite common to perform cost-benefit analyses before financing environmental projects like the creation of a national park or measures to improve water quality etc. It has also become customary to analyze people's preferences for environmental goods in the context of damage assessment after environmental accidents, especially in the United States. ${ }^{9}$ Therefore, it is surprising and not consistent with the principles of consumer sovereignty that citizen preferences should not matter for that part of environmental policy which is intended to reduce environmental deterioration like emission trading. It is not enough, of course, to include citizens as "producers", i. e. as polluters, into the emission trading mechanism since, as welfare theory tells us, it is rather their "private side" or their role as consumers that should be the guideline for public policy. Or, as William Hutt (1936 / 1990, p. 257) puts it: "In regarding the individual as a consumer, we do not see him in his full relationship to society. He is usually also a producer. But as a producer he is the servant of the community." And, somewhat below: "As a 'consumer', each directs. As a 'producer', each obeys." In the process of traditional emission trading policy it is, as was shown above, just the other way round.

\section{An alternative distribution mechanism for TEPs}

In order to integrate citizens into the emission trading system we propose a policy which lies between the ideal of a first-best Pigovian solution on the one hand and the total neglect of human preferences as it is common in actual emission trading systems on the other. We suggest that government after fixing the overall emission limit $\overline{\mathrm{E}}$ prints the corresponding number of emission certificates and distributes them for free to the private households. If a household $\mathrm{h} \in$ $\{1,2, \ldots, \mathrm{H}\}$ obtains $\overline{\mathrm{e}}^{\mathrm{h}}$ TEPs the overall emission limit $\overline{\mathrm{E}}$ equals the sum of the individual TEP holdings of the households:

$$
\sum_{\mathrm{h}=1}^{\mathrm{H}} \overline{\mathrm{e}}^{\mathrm{h}}=\overline{\mathrm{E}}
$$

9 As a consequence of the Comprehensive Environmental Response, Compensation and Liability Act (CERCLA) of 1980 it is possible for the government in the U. S. to sue any person or firm for compensation that is deemed responsible for contaminating the environment. Since 1989 compensation is demanded not only for lost use values but also for destroyed nonuse values of natural goods which means that compensation payments after a deterioration of environmental quality are directly linked to people's preferences (cf. e. g. Portney 1994, p. 9). 
The individual allotments $\overline{\mathrm{e}}^{\mathrm{h}}$ can, of course, be different for different households $\mathrm{h}$. Since households can sell the permits and buy consumption goods from the returns from this sale the assignment of $\overline{\mathrm{e}}^{\mathrm{h}}$ TEPs to a household $\mathrm{h}$ has the same impact on household utility as a lumpsum payment. Therefore, the choice of the distribution mode for the TEPs can be viewed as an additional instrument of the government's redistribution policy like the choice of the income tax scale or the transfer mechanism of the social security system.

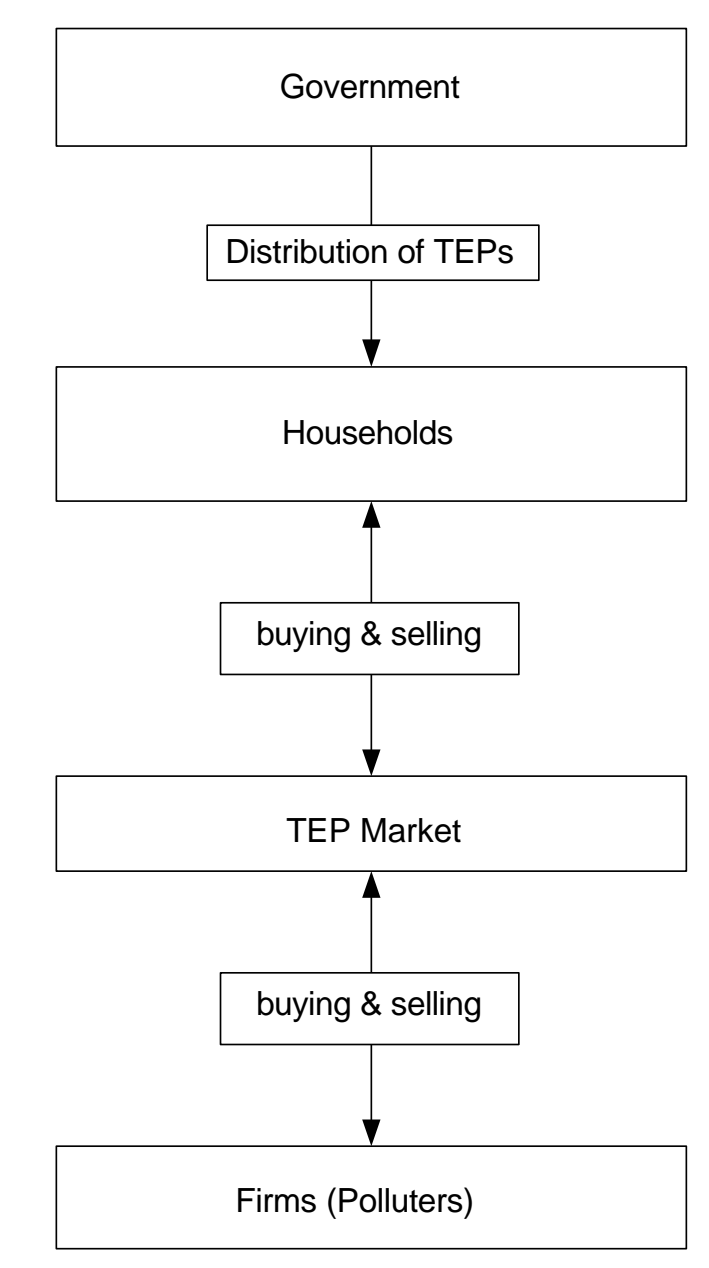

- fig. 3: Considering Household Preferences

It is clear that permits which are sold in the TEP market lead to emissions in the same amount while the quantity $\mathrm{e}^{\mathrm{h}}$ withheld by household $\mathrm{h}$ leads to a cutback of the overall emissions and, therefore, reduces the overall emission target $\overline{\mathrm{E}}$ set by the government. This means that households have the power to tighten the government's emission restriction $\overline{\mathrm{E}}$ by hoarding emission permits so that actual overall emissions $\overline{\mathrm{E}}^{\mathrm{H}}$ as enforced by the households turn out to be

(9) $\quad \overline{\mathrm{E}}^{\mathrm{H}}=\sum_{\mathrm{h}=1}^{\mathrm{H}}\left(\overline{\mathrm{e}}^{\mathrm{h}}-\mathrm{e}^{\mathrm{h}}\right) \leq \overline{\mathrm{E}}$. 
This implies that with such a TEP system the property right to nature is reallocated to the households - at least to the extent of the overall emission limit $\overline{\mathrm{E}}$. Households have the possibility to withhold a part or all of the distributed TEPs instead of selling them and, thereby, reduce the actual emissions according to their personal preferences. Such a system would involve households at least partially in the social abatement decision process instead of excluding them as in the traditional system. The main features of this kind of TEP system are illustrated in figure 3 .

Another important advantage of admitting households as traders in the TEP market where they can sell or buy permits is that this increases the number of agents in the permit market considerably as compared to the traditional TEP regime so that the possibilities for strategic manipulations of the market are significantly reduced. Therefore, returning the property right to the environment to its "natural" owners, i. e. the citizens, is not only justified on moral or ethical grounds but also avoids the economic drawbacks of the traditional TEP systems due to "thin markets" which are typical for the existing emission trading systems. In this sense the involvement of households in the emission trade implies also an improvement of market efficiency.

\section{Psychological considerations: incentives to withhold TEPs}

The question arises why households should hoard emission permits instead of selling them and buying consumption goods instead. To answer this question it is helpful to get a proper idea of the household's decision problem. For this purpose let us first specify the household budget constraint. We assume that private households own the primary resources of the economy. They can be used as inputs in production and at least some of them can also be consumed directly by the households (like e. g. time or land). We assume that each household $\mathrm{h}$ is endowed with a stock $\overline{\mathrm{y}}^{\mathrm{h}} \in \mathfrak{R}_{+}^{\boldsymbol{M}}$ of these resources which it can either consume or sell in the respective market. ${ }^{10}$ The receipts from the sale of resources is one of the two sources of household income. The other source is the sale of emission permits out of the stock $\overline{\mathrm{e}}^{\mathrm{h}}$ that the household obtains from government.

From this income household $\mathrm{h}$ has to finance its market consumption (which is denoted by the vector $\mathrm{x}^{\mathrm{h}} \in \mathfrak{R}_{+}^{N}$ ) at market prices $\mathrm{p} \in \mathfrak{R}_{++}^{N}$, so that its consumption expenditures are restricted by the budget constraint

$$
p x^{h} \leq q\left(\bar{y}^{h}-y^{h}\right)+p_{e}\left(\bar{e}^{h}-e^{h}\right) \quad(h=1,2, \ldots, H)
$$

where $\mathrm{q} \in \mathfrak{R}_{++}^{M}$ is the vector of factor prices and $\mathrm{p}_{\mathrm{e}}$ denotes the price of the emission permits. ${ }^{11}$ The term $\mathrm{q}\left(\overline{\mathrm{y}}^{\mathrm{h}}-\mathrm{y}^{\mathrm{h}}\right)$ comprises a household's conventional factor income while

10 By $\mathfrak{R}_{+}^{\boldsymbol{M}}$ we denote the non-negative orthant of the M-dimensional Euclidian space. Analogously, $\mathfrak{R}_{++}^{\boldsymbol{M}}$ is the positive orthant of the M-dimensional Euclidian space.

11 It should be clear that not each household is necessarily endowed with each kind of primary factor, i. e. some of the elements of the vector $\overline{\mathrm{y}}^{\mathrm{h}}$ can be zero. 
$\mathrm{p}_{\mathrm{e}}\left(\overline{\mathrm{e}}^{\mathrm{h}}-\mathrm{e}^{\mathrm{h}}\right)$ equals its income from the sale of the production factor "environment". Of course, a household can consume more of some primary resources $\mathrm{y}_{\mathrm{m}}$ than it is endowed with (so that $\mathrm{y}_{\mathrm{m}}^{\mathrm{h}}>\overline{\mathrm{y}}_{\mathrm{m}}^{\mathrm{h}}$ for some $\mathrm{m} \in\{1,2, \ldots, \mathrm{M}\}$ ), and the same is true for the TEPs, but the sum on the right hand side of (10) must always be nonnegative. This means that households can act as buyers and as sellers of primary resources and TEPs.

\section{Preferences}

If we want to go more deeply into a household's potential motivation to retain at least some part of the TEPs $\bar{e}^{\mathrm{h}}$ instead of selling them all we have to form a more detailed idea of its preferences. It is assumed that a household $\mathrm{h}$ obtains satisfaction from its market consumption $\mathrm{x}^{\mathrm{h}}$ and from its consumption $\mathrm{y}^{\mathrm{h}}$ of primary resources which could otherwise be sold in the market. Additionally, a household may derive utility from environmental quality which we shall denote by $\mathrm{z}$ and which is the same for all households since it is a pure public good.

The influence of $\mathrm{z}$ on household utility depends on what kind of pollutant is meant by $\mathrm{z}$. If we are talking about air or water quality or natural amenities this influence might be rather important. In the case of greenhouse gas emissions like carbon dioxide, methane, nitrogen oxide or CFCs a close relationship to utility is not very plausible since people do not sense changes in the concentration of such gases directly. At best they read about it in the papers or they are informed otherwise by the media. All the more it is amazing that in spite of the impossibility of personal perception of greenhouse gases, in many countries people are ready or even eager to make personal sacrifices for the sake of greenhouse gas reductions. They call for $\mathrm{CO}_{2}$ taxes or for the introduction of TEP systems which both result in higher commodity prices and, with incomes being constant, in reduced market consumption.

One possible explanation why people are willing to make sacrifices for environmental improvements which they personally do not even perceive might be the existence of what Andreoni (1989 and 1990) calls "impure altruism". In the context of greenhouse gas abatement this means the possibility that people do not really care for the state of the atmosphere but they feel a "warm glow" when they think they are doing "something good" or charitable. By sacrificing private income or consumption for $\mathrm{CO}_{2}$ abatement they derive (a basically egoistic form of) utility from the good deed itself and not from its consequences for something so abstract as the future world climate. In our model people can engender this warm glow feeling by retaining a part of their initial endowment $\bar{e}^{\mathrm{h}}$ of TEPs because hoarding TEPs means reducing greenhouse gas emissions by foregoing market consumption.

The existence of impure altruism seems to be a convincing explanation for the empirically observable desire of many people to give up certain present utility from private market consumption for uncertain future utility from the possible prevention of prospective climate deterioration. True intergenerational altruism, of course, would be another explanation. But from the true altruism point of view the world climate is a pure public good which raises all the questions and imponderables known from the "private provision of a public good" debate. This refers especially to the question of free riding, because for the world climate it does not matter who does the good deed of reducing $\mathrm{CO}_{2}$ emissions. Therefore, pure altruism does not seem to be a convincing explanation for the empirically observable desire of people to sacrifice private consumption for climate improvements that benefit future generations. 
Considering impure altruism in our model means that hoarding TEPs has a double effect on household utility: an indirect effect which is brought about by the consequences of reducing emissions for environmental quality and a direct effect which arises from the act of hoarding itself. This means that a household $h$ receives utility from three different sources: from its consumption of the market goods $x^{\mathrm{h}}$, from the retained part $\mathrm{y}^{\mathrm{h}}$ of its initial endowment of primary resources $\bar{y}^{\mathrm{h}}$, and from its withheld TEPs $\mathrm{e}^{\mathrm{h}}$. Integrating these different effects into the household utility function yields

$$
U^{h}=u^{h}\left(x^{h}, y^{h}, z\left(\sum_{i=1}^{H} e^{i}\right), e^{h}\right) \quad(h=1,2, \ldots, H)
$$

where $\mathrm{U}^{\mathrm{h}}$ is the utility level attained by household $\mathrm{h}$ and $\mathrm{u}^{\mathrm{h}}(\ldots)$ is the utility function. Environmental quality $\mathrm{z}$, which is the same for all households, depends on the sum of the retained TEPs over all households (including household $h$ ), since each retained TEP means one ton less of e. g. $\mathrm{CO}_{2}$ and, therewith, an improvement of environmental quality.

We see that the number $\mathrm{e}^{\mathrm{h}}$ of TEPs hoarded by household $\mathrm{h}$ enters the utility function in two ways: first, indirectly by influencing environmental quality and, second, directly by generating a "warm glow of giving". The first effect, which could be described as the pure public good effect of hoarding TEPs, is given by

$$
\frac{\partial u^{h}}{\partial z} \cdot \frac{\partial z}{\partial e^{h}} \geq 0 \quad \text { with } \quad \frac{\partial u^{h}}{\partial z} \geq 0 \text { and } \frac{\partial z}{\partial e^{h}} \geq 0
$$

The second effect, which could be called the warm glow effect of hoarding TEPs, equals the partial derivative of the utility function with respect to $\mathrm{e}^{\mathrm{h}}$, i. e.

$$
\frac{\partial u^{h}}{\partial e^{h}} \geq 0
$$

The household`s optimization problem becomes now

$$
\begin{aligned}
& \max _{\mathrm{x}^{\mathrm{h}}, \mathrm{y}^{\mathrm{h}}, \mathrm{e}^{\mathrm{h}} \in X^{\mathrm{h}}} \mathrm{u}^{\mathrm{h}}\left(\mathrm{x}^{\mathrm{h}}, \mathrm{y}^{\mathrm{h}}, \mathrm{z}\left(\sum_{\mathrm{i}=1}^{\mathrm{H}} \mathrm{e}^{\mathrm{i}}\right), \mathrm{e}^{\mathrm{h}}\right) \\
& \text { where } \boldsymbol{X}^{\mathrm{h}}=\left\{\left[\mathrm{x}^{\mathrm{h}}, \mathrm{y}^{\mathrm{h}}, \mathrm{e}^{\mathrm{h}}\right] \mid \mathrm{px} \mathrm{x}^{\mathrm{h}} \leq \mathrm{q}\left(\overline{\mathrm{y}}^{\mathrm{h}}-\mathrm{y}^{\mathrm{h}}\right)+\mathrm{p}_{\mathrm{e}}\left(\mathrm{e}^{\mathrm{h}}-\mathrm{e}^{\mathrm{h}}\right)\right\} \quad(\mathrm{h}=1,2, \ldots, \mathrm{H}) .
\end{aligned}
$$

From this maximization problem we obtain the standard optimality conditions for the consumption of the market goods 

(a) $\frac{\partial u^{h}}{\partial x_{n}^{h}}(*)=\lambda^{h^{*}} p_{n}$
$(\mathrm{n}=1,2, \ldots, \mathrm{N})$
(b) $\frac{\partial \mathrm{u}^{\mathrm{h}}}{\partial \mathrm{y}_{\mathrm{m}}^{\mathrm{h}}}(*)=\lambda^{\mathrm{h}^{*}} \mathrm{q}_{\mathrm{m}}$
$(\mathrm{m}=1,2, \ldots, \mathrm{M})$

where $\lambda^{\mathrm{h}_{*}}$ is the marginal utility of income in household equilibrium and $\left(^{*}\right)$ denotes the equilibrium values of the arguments of the respective function, in this case of the utility function. To specify the form of the optimality conditions for the TEP demand we must distinguish between different assumptions with respect to household preferences.

\section{The general case}

If we take into account that a household receives utility from environmental quality $\mathrm{z}$ as well as from its personal stock of hoarded TEPs $\mathrm{e}^{\mathrm{h}}$, where it can choose only $\mathrm{e}^{\mathrm{h}}$ directly, the respective optimality condition becomes

$$
\frac{\partial u^{\mathrm{h}}}{\partial \mathrm{z}}(*) \cdot \frac{\partial \mathrm{z}}{\partial \mathrm{e}^{\mathrm{h}}}(*)+\frac{\partial \mathrm{u}^{\mathrm{h}}}{\partial \mathrm{e}^{\mathrm{h}}}(*)=\lambda^{\mathrm{h}^{*}} \mathrm{p}_{\mathrm{e}}
$$

We observe that the first term on the left-hand side equals the public good effect (12) of hoarding TEPs while the second term is the warm glow effect (13). Since both effects are nonnegative they both influence the demand for TEPs in the same direction.

To illustrate the relation between these two effects we make use of a simple diagram. If we combine (16) with the market demand condition (15a) we obtain the marginal rate of substitution between TEPs and market goods as

$$
\frac{\frac{\partial \mathrm{u}^{\mathrm{h}}}{\partial \mathrm{z}} \cdot \frac{\partial \mathrm{z}}{\partial \mathrm{e}^{\mathrm{h}}}+\frac{\partial \mathrm{u}^{\mathrm{h}}}{\partial \mathrm{e}^{\mathrm{h}}}}{\frac{\partial \mathrm{u}^{\mathrm{h}}}{\partial \mathrm{x}_{\mathrm{n}}^{\mathrm{h}}}}(*)=\frac{\mathrm{p}_{\mathrm{e}}}{\mathrm{p}_{\mathrm{n}}}
$$

In figure 4 we have the indifference curves for two versions of the household utility function: $\mathrm{U}_{\mathrm{PG}}$ stands for the case where only the public good effect is considered (i. e. $\partial \mathrm{u}^{\mathrm{h}} / \partial \mathrm{e}^{\mathrm{h}}=0$ ) and $\mathrm{U}_{\mathrm{WG}}$ is the indifference curve according to (17) where also the warm glow effect is allowed for. From (17) it is apparent that the indifference curves become steeper when the warm glow effect is included in the analysis. This confirms the supposition that the pure public good effect is reinforced by the warm glow effect, i. e. the warm glow effect leads to an increased demand for TEPs (from $\mathrm{e}_{\mathrm{PG}}^{\mathrm{h}}$ to $\mathrm{e}_{\mathrm{WG}}^{\mathrm{h}}$ in figure 4). ${ }^{12}$

12 We assume that environmental quality as well as warm glow are non-inferior goods. 


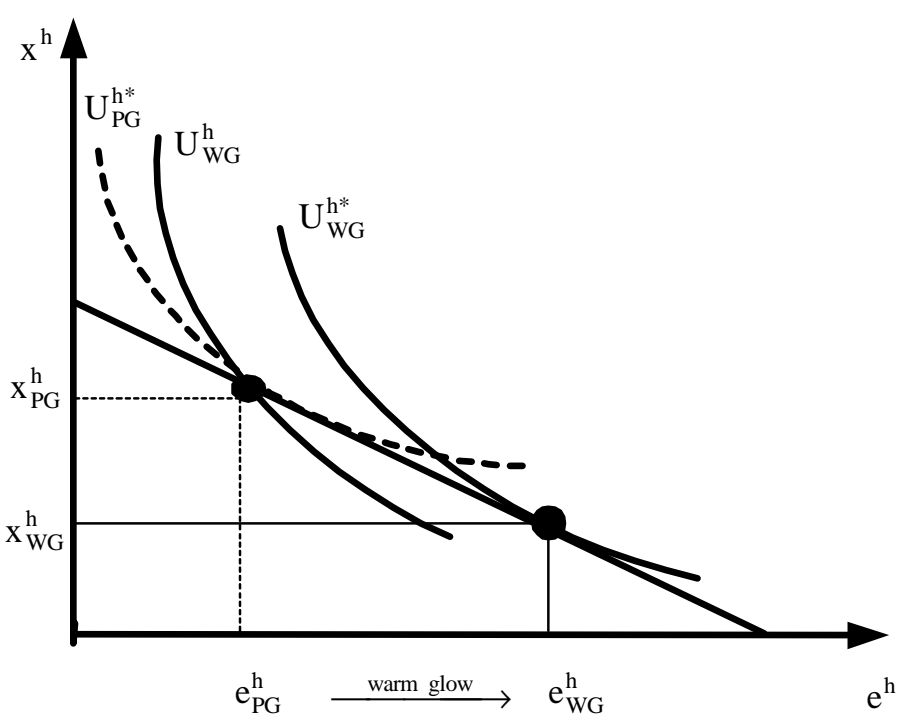

- fig. 4 -

Figure 5 illustrates the case where the pure public good effect is smaller than the TEP price (in utility units) for all positive values of $\mathrm{e}^{\mathrm{h}}$. In this case the budget line is steeper than the indifference curve for the utility function without warm glow so that the household does not buy any TEPs for environmental reasons alone $\left(\mathrm{e}_{\mathrm{PG}}^{\mathrm{h}}=0\right)$. If there is a positive demand for TEPs at all it arises only from the household's desire for warm glow $\left(\mathrm{e}_{\mathrm{WG}}^{\mathrm{h}}>0\right)$. Otherwise the TEP demand is zero.

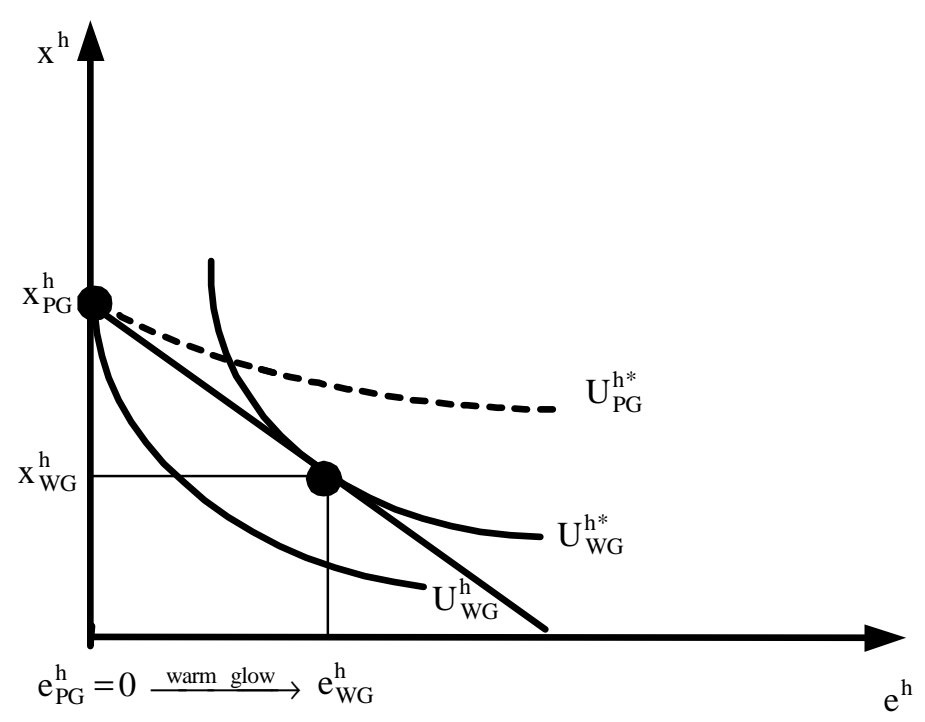

- fig. 5 - 
These considerations confirm that the demand for TEPs can be separated into two independent effects, i. e. the public good effect and the warm glow effect. Each of these two effects stands for a different motivation of a household to hoard TEPs instead of selling them. In the following subsection we shall have a closer look at each of these effects separately by considering two special cases of a preference ordering. Let us start with the pure public good case where no warm glow effect exists.

\section{The pure public good case}

In this section we assume that the household under consideration does not care for warm glow feelings so that

$$
\frac{\partial u^{h}}{\partial e^{h}}=0
$$

As a consequence the optimality condition (16) becomes

$$
\frac{\partial \mathrm{u}^{\mathrm{h}}}{\partial \mathrm{z}}(*) \cdot \frac{\partial \mathrm{z}}{\partial \mathrm{e}^{\mathrm{h}}}(*)=\lambda^{\mathrm{h}^{*}} \mathrm{p}_{\mathrm{e}}
$$

We see that the magnitude of the public good effect depends on the marginal utility of environmental quality $\partial \mathrm{u}^{\mathrm{h}} / \partial \mathrm{z}$ on the one hand and the household's judgement of its own influence on environmental quality $\partial \mathrm{z} / \partial \mathrm{e}^{\mathrm{h}}$ on the other.

\section{(i) Indifference with respect to environmental quality}

As explained before, in the case of greenhouse gases like $\mathrm{CO}_{2}$, methane etc. it is rather unlikely that a household's utility is directly affected by the concentration of these gases, so that low values of $\partial \mathrm{u}^{\mathrm{h}} / \partial \mathrm{z}$ whenever $\mathrm{z}$ denotes this kind of emissions which are typically regulated by TEP systems. In the extreme case where

$$
\frac{\partial u^{h}}{\partial z}=0
$$

the left hand side of (19) is equal to zero and (19) is not fulfilled as an equation since the marginal utility of income as well as the TEP price are strictly positive. The respective KuhnTucker condition is then fulfilled as an inequality according to

$$
\left(\frac{\partial \mathrm{u}^{\mathrm{h}}}{\partial \mathrm{z}}(*) \cdot \frac{\partial \mathrm{z}}{\partial \mathrm{e}^{\mathrm{h}}}(*)-\lambda^{\mathrm{h}^{*}} \mathrm{p}_{\mathrm{e}}\right)<0
$$

so that the demand for TEPs $\mathrm{e}^{\mathrm{h}}$ must be zero in this case because of the corresponding complementary slackness condition 


$$
\left(\frac{\partial u^{h}}{\partial z}(*) \cdot \frac{\partial z}{\partial e^{h}}(*)-\lambda^{h^{*}} p_{e}\right) \cdot e^{h}=0
$$

The economic explanation of this result is rather straightforward: if you do not care for the world climate and you do not bother about good deeds either, you have no incentive to buy TEPs instead of market consumption goods. Such an indifference with respect to environmental quality is not implausible if greenhouse gases like $\mathrm{CO}_{2}$ are concerned.

\section{(ii) The tragedy of the commons}

An analogous argument holds if a household appreciates an improvement of environmental quality (i. e. $\partial \mathrm{u}^{\mathrm{h}} / \partial \mathrm{z}>0$ ) but thinks that its own possibilities to contribute to such an improvement are very small or zero, i. e.

$$
\frac{\partial \mathrm{z}}{\partial \mathrm{e}^{\mathrm{h}}}=0
$$

Such a combination of a positive marginal utility of environmental quality on the one hand and a personal impact factor $\partial \mathrm{z} / \partial \mathrm{e}^{\mathrm{h}}$ of zero is typical for what is usually called the "tragedy of the commons": 13 the contradiction between social rationality on the one hand, which demands a preservation of the public good "environment", and individual rationality, which tells the individual that it is not worthwhile for him personally to make any sacrifices for the provision of this public good, on the other. This kind of argument makes sense, especially, with respect to the greenhouse effect since a single citizen's influence on the world climate is so small that the benefits he receives from his personal contribution (e.g. by hoarding TEPs) can be neglected. In such a case it seems reasonable from an individual point of view not to hoard any TEPs. This consideration is confirmed by condition (21) which implies that the demand for TEPs must zero under these circumstances.

\section{(iii) Free riding}

It is, of course, also possible that the marginal utility of environmental quality and the personal impact factor are both positive and the demand for TEPs is all the same zero. This is the typical "free riding" case, where an individual appreciates environmental quality $\left(\partial \mathrm{u}^{\mathrm{h}} / \partial \mathrm{z}>0\right)$ and is well aware that he could do something about it $\left(\partial \mathrm{z} / \partial \mathrm{e}^{\mathrm{h}}>0\right)$ but, nevertheless, does not contribute to the provision of the public good "environmental quality" (i. e. $\mathrm{e}^{\mathrm{h}}=0$ ) because he hopes that others will do it and he can consume the improved environmental quality for free. Such a household will not buy any TEPs for purely strategic reasons.

For the pure public good case in which no warm glow is desired we have described three special kinds of preference orderings which might induce a household to sell its whole stock of TEPs: indifference with respect to environmental quality, the "tragedy of the commons"-case, and the "free riding" case. If all households of an economy have one of these exceptional preference orderings the overall emission limit $\overline{\mathrm{E}}$ set by the government is not changed

13 This concept was introduced into the literature by Hardin (1968). 
through the households' involvement in the TEP market: In this case a TEP system with household participation leads to the same TEP allocation as auctioning or grandfathering. But even in such a situation where all households refuse to play an active part in the regulation of greenhouse gas emissions there is no negative impact on the level of climate preservation as compared to the traditional TEP systems.

\section{The pure warm glow case}

As explained above the most convincing explanation for people's willingness to make personal sacrifices for some good cause that does not benefit them directly is the existence of impure altruism, i. e. the pleasure derived from the knowledge that one is doing something good. The desire for this "warm glow of giving", as Andreoni (1990) called it, provides a sensible reason for people to withhold some of the TEPs allotted to them instead of selling them to buy market goods. For impure altruists the actual effect of their hoarding TEPs on world climate does not matter. They are only interested in the feeling of being good citizens who have done their bit for the good cause, while the cause itself is completely irrelevant. This motivation, of course, eliminates the public good character of TEPs since the good citizen can get the desired warm glow feeling only if he retains some TEPs himself, delegation is not possible. Consequently, in the pure warm glow case with

$$
\frac{\partial \mathrm{u}^{\mathrm{h}}}{\partial \mathrm{z}}(*)=0 \quad \text { and } \quad \frac{\partial \mathrm{z}}{\partial \mathrm{e}^{\mathrm{h}}}\left(\mathrm{e}^{\mathrm{h}^{*}}\right) \geq 0
$$

there is no incentive for free riding because one cannot derive a warm glow from the charity of others. In this case TEPs can be treated like ordinary market goods which are bought in accordance with the optimality condition

$$
\frac{\partial u^{h}}{\partial e^{h}}(*)=\lambda^{h^{*}} p_{e}
$$

In fig. 6 the pure warm glow case where (22) holds is illustrated in analogy to figure 5. The indifference curve $U_{P G}$ for a preference ordering without impure altruism is a straight line parallel to the $\mathrm{e}^{\mathrm{h}}$-axis because hoarding TEPs generates no utility at all in this case. An impure altruistic citizen on the other hand with indifference curves $U_{W G}$ can increase his utility from $\mathrm{U}_{\mathrm{WG}}^{\mathrm{h}}$ to $\mathrm{U}_{\mathrm{WG}}^{\mathrm{h}^{*}}$ if he is given the opportunity of hoarding some TEPs as can also be seen from fig. 6 . 


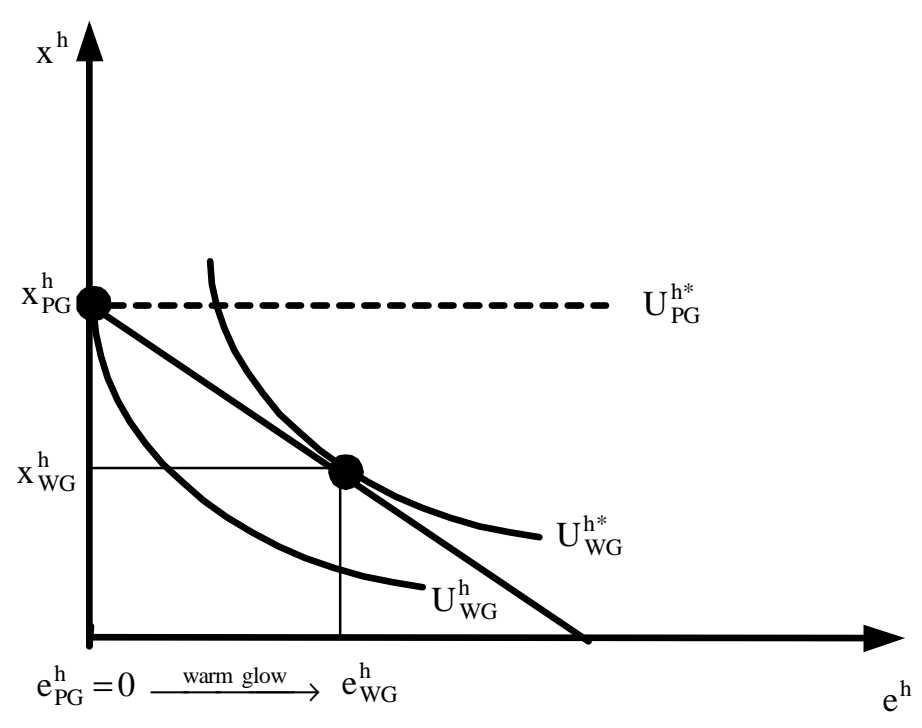

- fig. 6 -

In table 1 the different special cases from above are summarized. We see that, if we disregard the warm glow argument (i. e. $\partial \mathrm{u}^{\mathrm{h}} / \partial \mathrm{e}^{\mathrm{h}}=0$ ), there are three main reasons why a household might sell all of its initial endowment $\overline{\mathrm{e}}^{\mathrm{h}}$. One is indifference with respect to the pollutant in question. This possibility, which is shown in the first line of table 1, can certainly not be ruled out whenever we talk about greenhouse gases because these gases and the consequences of their discharge into the environment cannot be sensed directly by human beings. These consequences appear quite abstract and theoretical to many people, they are rather uncertain, and they lie far in the future. Therefore, many people do not really bother for greenhouse gas emissions.

The second reason not to hoard TEPs for purely environmental reasons is that many people feel that they as individuals have no or nearly no influence on a global environmental problem like the greenhouse effect $\left(\partial \mathrm{z} / \partial \mathrm{e}^{\mathrm{h}}=0\right)$. Therefore, they think it is not worthwhile to retain any of their TEPs because the resulting effect on environment will be irrelevant, anyway (cf. line 2 of table 1). Even if people do care for the greenhouse effect and if they believe that their personal sacrifice makes sense with respect to the greenhouse problem there are still strong incentives for an individual not to hoard TEPs because they regard the world climate as a pure public good (which is correct if we disregard impure altruism). This means that people cannot be excluded from its consumption even if they do not contribute to its provision and also the quality of their consumption is not affected by their personal contribution. Therefore, any personal contribution to the provision of that good (i. e. any retained emission permit) would appear to them as a waste of income and private consumption (line 3 in table 1).

In spite of all these reasons for non-cooperative behavior with respect to the provision of the public good "world climate" it can be observed that many people are willing and even keen to make personal sacrifices (in terms of income or time) to prevent a deterioration of the world climate. This fact might be interpreted as an empirical evidence for the hypothesis that people do not behave as rational and egoistic as household theory would suggest. On the other hand it 
would be surprising if so many households acted out of mere irrationality. This consideration suggests that there exist other rational incentives to contribute to the preservation of the environment. A rather plausible motivation might be Andreoni's impure altruism as shown in line 4 of table 1. Applied to our problem impure altruism can produce a positive household demand for TEPs even in a society of free riders or a society that does not believe in the sense of individual contributions to a better environment.

\begin{tabular}{|c||c|c|c|c|}
\hline case Iutility fct. & $\frac{\partial \mathrm{u}^{\mathrm{h}}}{\partial \mathrm{z}}$ & $\frac{\partial \mathrm{z}}{\partial \mathrm{e}^{\mathrm{h}}}$ & $\frac{\partial \mathrm{u}^{\mathrm{h}}}{\partial \mathrm{e}^{\mathrm{h}}}$ & $\mathrm{e}^{\mathrm{h}}$ \\
\hline $\begin{array}{c}\text { indifference with } \\
\text { respect to pollution }\end{array}$ & $\mathbf{0}$ & $\geq 0$ & 0 & 0 \\
\hline $\begin{array}{c}\text { tragedy of the } \\
\text { commons }\end{array}$ & $>0$ & $\mathbf{0}$ & 0 & 0 \\
\hline $\begin{array}{c}\text { free riding } \\
\text { pure warm glow case }\end{array}$ & 0 & $>0$ & $\mathbf{0}$ & 0 \\
\hline
\end{tabular}

- table 1 -

\section{A note on pure altruism}

After this detailed discussion of impure altruism as an incentive for hoarding TEPs one might ask why pure altruism is not considered here with comparable scrutiny. The reason is that pure altruism would not change our argumentation as compared to the pure public good case. In principle, there are two main kinds of altruism treated in the economics literature: paternalistic altruism and individualistic altruism. ${ }^{14}$

If we consider paternalistic altruism where the present generation cares for the future climate $\mathrm{z}$ no matter if the future generations do we have utility functions of the general form

$$
\mathrm{U}^{\mathrm{h}}=\mathrm{u}^{\mathrm{h}}\left(\mathrm{x}^{\mathrm{h}}, \mathrm{y}^{\mathrm{h}}, \mathrm{z}\left(\sum_{\mathrm{i}=1}^{\mathrm{H}} \mathrm{e}^{\mathrm{i}}\right)\right) .
$$

This is the typical utility function for the pure public good case treated above. The household cares for the future climate $\mathrm{z}$ but it does not matter who contributes to its improvement. Therefore, the tragedy of the commons problem as well as the free riding discussion from above apply here analogously.

14 For this distinction see e. g. Madariaga / McConnell (1987). 
If, alternatively, we deal with individualistic altruism where people today care for the utility $\mathrm{v}(\cdot)$ of future generations and take into account the dependence of future utility on future climate we obtain a utility function of the general type

$$
\mathrm{U}^{\mathrm{h}}=\mathrm{u}^{\mathrm{h}}\left(\mathrm{x}^{\mathrm{h}}, \mathrm{y}^{\mathrm{h}}, \mathrm{v}\left(\mathrm{z}\left(\sum_{\mathrm{i}=1}^{\mathrm{H}} \mathrm{e}^{\mathrm{i}}\right)\right)\right) \text {. }
$$

As in the paternalistic case we end up here with the typical public good problems of free riding and the tragedy of the commons. Therefore, in spite of the fact that true altruism might provide a compelling argument for the hoarding of TEPs at first sight it turns out that the typical public good arguments against individual cooperation hold here so that the existence of purely altruistic preferences does not change our previous discussion. The most convincing incentives for the hoarding of TEPs by individual households result from the existence of impure altruism and the desire for Andreoni's warm glow.

\section{Efficiency considerations}

In the last section we showed how a TEP system that involves households as participants in the permit market might work. It became apparent that there are incentives for households to retain at least some of the TEPs allocated to them. Therefore, we can expect that the TEP allocation resulting from such a system will differ from the allocation that results from the traditional emission trading mechanism because a smaller number of TEPs will be available for polluters (both allocations may coincide only if all TEPs are sold to the firms). In order to test the social desirability of such a change we have to scrutinize the efficiency properties of our new TEP system and to compare them to the respective properties of the traditional TEP systems. In the following subsections we shall deal in turn with ecological efficiency, cost efficiency and Pareto efficiency.

The TEP system with household participation as proposed here differs in two ways from the traditional TEP systems. First and most important, households are allowed to withhold some TEPs from the polluters and even to buy TEPs in addition to their initial endowment which gives them the possibility to influence the total quantity of emissions. Second, the initial endowment of TEPs is allocated to households (instead of firms or government) for free which symbolizes that the property right to the environment is given to the households. This second characteristic of our TEP system has the same impact on household consumption and household utility as a lump-sum transfer, i. e. a mere income effect. For the efficiency comparison to be made in this section the differences in income effects are irrelevant and should be eliminated. For that purpose we assume for the following analysis that in all three cases of TEP systems (grandfathering, auctioning, household participation) the returns from the sale of the TEPs are transformed as lump-sum transfers to the household sector (according to the same distribution scheme). 


\section{Ecological efficiency}

By the ecological efficiency of an environmental policy instrument we mean its capacity to realize a given ecological target, in our case an emission target. From the environmental economics literature we know that the ecological efficiency of the traditional emission trading systems, i. e. of auctioning and grandfathering, is very high ${ }^{15}$ since the emission limit $\overline{\mathrm{E}}$ as set by the government cannot be transgressed by polluters (at least not legally). This is an important difference between emission trading and e. g. the use of eco-taxes. The ecological difference between auctioning and grandfathering on the one hand and our allocation system where households obtain the TEPs on the other is that the overall emission limit $\overline{\mathrm{E}}$ as set by the government can be tightened by households through hoarding TEPs so that $\overline{\mathrm{E}} \mathrm{H} \leq \overline{\mathrm{E}}$ according to (9). Therefore, the modification of the emission trade as proposed in this paper does not jeopardize the ecological objectives of the government represented by $\overline{\mathrm{E}}$ since this emission limit can never be transgressed. The possibilities of the private households to interfere with the government's environmental policy by enforcing their own emission target $\overline{\mathrm{E}}^{\mathrm{H}}$ are restricted to the interval

$$
0 \leq \overline{\mathrm{E}}^{\mathrm{H}} \leq \overline{\mathrm{E}}
$$

In the ecological "worst case" when all households act as free riders and no one cares for a warm glow total household demand for TEPs becomes zero. But even then the overall emission level $\overline{\mathrm{E}}$ is preserved as can be seen from (9), i. e.

$$
\sum_{h=1}^{H} e^{h}=0 \Rightarrow \bar{E}^{H}=\bar{E} .
$$

This shows that even if the most pessimistic critics of citizen participation in environmental protection are right and there is no desire for warm glow and only free riding instead, the quantity of emissions generated by the TEP system with household participation is not larger than in the traditional auctioning or grandfathering case.

Also the other extreme case of preferences in which households are not willing to sell any of their TEPs to polluters does not harm the ecological objectives of government. On the contrary, in this case where

$$
\sum_{h=1}^{\mathrm{H}} \mathrm{e}^{\mathrm{h}}=\sum_{\mathrm{h}=1}^{\mathrm{H}} \overline{\mathrm{e}}^{\mathrm{h}} \Rightarrow \overline{\mathrm{E}}^{\mathrm{H}}=0
$$

holds, emissions are reduced to zero. This situation could be explained with an extreme desire for warm glow or with an extreme craving for an intact environment in combination with the complete absence of free riding or tragedy-of-the-commons pessimism or - outside our model and outside neo-classical household theory - with a lexicographic preference ordering, where the environmental protection is first priority. A reduction of total emissions to zero might, of course, be harmful to the production sector but it is not harmful to the environment and if households have such an extraordinary preference for climate protection this must be respected.

15 Cf. e. g.Klaasen / Försund (1994). 
In reality one probably has to deal with mixed preferences, i. e. with some free riders, some pure altruists, some environmentally ignorant households and some impure altruists. In such a typical situation some of the TEPs distributed to the households will be retained and some will be sold to polluters so that the effective emission level $\overline{\mathrm{E}}^{\mathrm{H}}$ will lie somewhere between 0 and $\overline{\mathrm{E}}$. But no matter if one of the extreme cases described above or the mixed preferences case comes into effect the emission limit $\overline{\mathrm{E}}$ will always be respected so that the ecological efficiency of a TEP system with household participation is always guaranteed. Comparing (24) to (3) or (6) we see that with respect to ecological efficiency a TEP system with household participation is at least as good as the traditional TEP systems but probably - in all cases but the special case (25) - it is better.

\section{Cost efficiency}

It is common knowledge that emission trading is an instrument of "high economic efficiency". What is meant here is the fact that tradable emission permits of the auctioning or grandfathering type do not discriminate between different uses of one and the same production factor, i. e. the marginal product of an input is the same in all its different uses. In this regard a TEP system has the same impact on the firm's production decision as a uniform per-unit tax on emissions. As was shown e. g. by Baumol and Oates (1971) in their seminal paper on the pricing and standards approach this condition is necessary for the realization of a given environmental target with minimal social costs.

The TEP system with household participation as proposed in this paper has the same economic impact on the firms' profit maximization conditions as TEP systems with government auctioning or grandfathering: firms hire inputs y and e until optimality conditions (4) and (5) are fulfilled. Together with technical efficiency and well-behaved production functions this ensures cost efficiency in the sense of Baumol and Oates. Therefore, regarding cost efficiency the TEP system with household participation proposed in this paper is equivalent to the traditional TEP systems.

\section{Pareto efficiency}

As a preliminary result we can state that a TEP system with household participation is equivalent to the traditional TEP systems with respect to (social) cost efficiency and at least as good (but probably better ) with respect to ecological efficiency. In this subsection we want to include household utility into our efficiency considerations which leads us to the problem of Pareto efficiency. To illustrate our considerations we use a simplified model with only two households and one aggregated production sector.

\section{The Pareto conditions}

Let us assume that both households have a utility function of the general form (11), i. e.

$$
\mathrm{U}^{\mathrm{h}}=\mathrm{u}^{\mathrm{h}}\left(\mathrm{x}^{\mathrm{h}}, \mathrm{y}^{\mathrm{h}}, \mathrm{z}\left(\sum_{\mathrm{i}=1}^{\mathrm{H}} \mathrm{e}^{\mathrm{i}}\right), \mathrm{e}^{\mathrm{h}}\right) \quad(\mathrm{h}=1,2)
$$


This utility function implies the option that one or both households are impure altruists. The production possibilities of our economy are given by the implicit production function

$$
\mathrm{F}\left(\mathrm{x}, \mathrm{y}^{\mathrm{U}}, \mathrm{e}^{\mathrm{U}}\right) \leq 0
$$

where the emissions $\mathrm{e}^{\mathrm{U}}$ represent the use of the environment as an input, i. e. as a sink for the emissions of the production sector. The emissions are treated analogously to the conventional market inputs $\mathrm{y}^{\mathrm{U}}$ for the production of the output vector $\mathrm{x}$.

We further assume that government sets an emission limit $\overline{\mathrm{E}}$ which must not be exceeded. Households and firms have to share this emission quota according to

(28) $e^{1}+e^{2}+e^{U} \leq \bar{E}$

where households "consume" emissions $\mathrm{e}^{\mathrm{h}}(\mathrm{h}=1,2)$ by preventing them. I. e. the quota $\overline{\mathrm{E}}$ can be used by firms (for production) or by households (to save the world climate or to generate a warm glow).

Accordingly the total quantities of primary resources $\bar{Y} \in \Re_{+}^{M}$ have to be distributed on households for consumption on the one hand and to the production sector as inputs on the other

(29) $y^{1}+y^{2}+y^{U} \leq \bar{Y}$.

From this simple model we obtain the standard Pareto conditions with respect to the optimal allocation of outputs $\mathrm{x}$ and primary resources $\mathrm{y}$ :

$$
\frac{\partial u^{1} / \partial y_{m}^{1}}{\partial u^{1} / \partial x_{n}^{1}}=\frac{\partial F / \partial y_{m}^{U}}{\partial F / \partial x_{n}^{U}}=\frac{\partial u^{2} / \partial y_{m}^{2}}{\partial u^{2} / \partial x_{n}^{2}} \quad(n=1,2, \ldots, N ; m=1,2, \ldots, M)
$$

The condition for the Pareto optimal distribution of the emissions is

$$
\begin{aligned}
& \frac{\frac{\partial u^{1}}{\partial z} \cdot \frac{\partial z}{\partial e^{1}}}{\partial u^{1} / \partial x_{n}^{1}}+\frac{\partial u^{1} / \partial e^{1}}{\partial u^{1} / \partial x_{n}^{1}}+\mu^{*} \cdot \frac{\frac{\partial u^{2}}{\partial z} \cdot \frac{\partial z}{\partial e^{1}}}{\partial u^{1} / \partial x_{n}^{1}}=-\frac{\partial F / \partial e^{U}}{\partial F / \partial x_{n}} \\
& =\frac{1}{\mu^{*}} \cdot \frac{\frac{\partial u^{1}}{\partial z} \cdot \frac{\partial z}{\partial e^{2}}}{\partial u^{2} / \partial x_{n}^{2}}+\frac{\partial u^{2} / \partial e^{2}}{\partial u^{2} / \partial x_{n}^{2}}+\frac{\frac{\partial u^{2}}{\partial z} \cdot \frac{\partial z}{\partial e^{2}}}{\partial u^{2} / \partial x_{n}^{2}} \quad\left(\begin{array}{l}
n=1,2, \ldots, N ; \\
m=1,2, \ldots, M
\end{array}\right),
\end{aligned}
$$

where $\mu^{*}$ is the conversion factor of utility of household 1 into utility of household 2 , i. e. ${ }^{16}$

16 The corresponding Lagrangean is:

$$
\mathrm{L}(\cdot)=\mathrm{u}^{1}\left(\mathrm{x}^{1}, \mathrm{y}^{1}, \mathrm{z}\left(\sum_{\mathrm{h}=1}^{\mathrm{H}} \mathrm{e}^{\mathrm{h}}\right), \mathrm{e}^{1}\right)+\mu \cdot\left(\mathrm{u}^{2}\left(\mathrm{x}^{2}, \mathrm{y}^{2}, \mathrm{z}\left(\sum_{\mathrm{h}=1}^{\mathrm{H}} \mathrm{e}^{\mathrm{h}}\right), \mathrm{e}^{2}\right)-\overline{\mathrm{U}}^{2}\right)
$$




$$
\mu^{*}=-\frac{d U^{2}}{d U^{1}}=\frac{\partial u^{1} / \partial x_{n}^{1}}{\partial u^{2} / \partial x_{n}^{2}}=\frac{\partial u^{1} / \partial y_{m}^{1}}{\partial u^{2} / \partial y_{m}^{2}} \quad\left(\begin{array}{l}
n=1,2, \ldots, N ; \\
m=1,2, \ldots, M
\end{array}\right)
$$

From the solution of our optimization problem we further obtain the conditions for efficient production (inequality (27) must be fulfilled as an equation in a Pareto optimum), for ecological efficiency according to (28), for an efficient use of the primary resources (inequality (29) must be fulfilled as an equation) and for cost efficiency (from the derivatives of the Lagrangean in FN 15 for $\mathrm{e}^{\mathrm{U}}$ and $\mathrm{y}_{\mathrm{m}}^{\mathrm{U}}$ ). In the following subsection we shall check to what extent these conditions for Pareto optimality are fulfilled by a TEP system with household participation as proposed in section 3 .

\section{Efficiency characteristics of a TEP system with household participation}

In the preceding subsections we showed that a TEP system with household participation fulfills the Pareto conditions of ecological efficiency and cost efficiency while an efficient allocation of market commodities $\mathrm{x}$ and y according to (29) and (30) is guaranteed by well-behaved utility and production functions and the existence of competitive markets. The only remaining problem is the Pareto optimal allocation of emissions according to (31).

From (31) it becomes obvious that household preferences should not be neglected whenever emission reductions are at stake unless in the exceptional case where no household cares either for environmental quality or for warm glow feelings. An optimal allocation of emissions, however, would require that no household acts as a free rider and no one is discouraged by the supposed insignificance of his possible contribution to a cutback of global emissions (i. e. there is no tragedy of the commons). Further, each household must bear in mind the external effects which its personal contribution to emission reduction by hoarding TEPs exerts on the utility of other households (according to the third term on the left-hand side and the first term on the right-hand side of (31)). Clearly, it would be naive to assume that these conditions are absolutely fulfilled in reality. But it would also be naive to believe that these effects are as irrelevant as economic theory would suggest. In experimental studies it was shown that households act much less rational in reality than in theory so that e. $\mathrm{g}$. the free riding problem is much less important in reality than it should be expected on theoretical grounds. ${ }^{17}$

Irrespective of these public good problems it is apparent from (31) that also the potential existence of impure altruism calls for an explicit consideration of household preferences with respect to an emission reduction. Households and firms are competing for emissions where firms want to discharge and households want to prevent emissions. The resulting distribution problem can be managed in a market system by implementing a TEP system with household participation as described in section 3. Each TEP stands e. g. for one ton of $\mathrm{CO}_{2}$ emissions. If the TEP is bought by a firm this means one more ton of $\mathrm{CO}_{2}$ emissions, if it is retained by a household this implies a reduction of total $\mathrm{CO}_{2}$ emissions by one ton (as compared to $\overline{\mathrm{E}}$ ) and it might give rise to warm glow.

$$
\alpha \cdot\left(\bar{E}-e^{1}-e^{2}-e^{U}\right)-\beta \cdot\left(\bar{Y}-y^{1}-y^{2}-y^{U}\right)-v \cdot F\left(x, y^{U}, e^{U}\right) \cdot
$$

17 Cf. e. g. the "classical" study of Bohm (1972), Schneider/ Pommerehne (1981), Andreoni (1995) or Cummings / Harrison / Rutström (1995). 
If no household cares for future climate $\mathrm{z}$ (so that $\partial \mathrm{u}^{\mathrm{h}} / \partial \mathrm{z}=0, \forall \mathrm{h}$ ) only the warm glow argument remains and optimality condition (31) becomes

$$
\frac{\partial u^{1} / \partial e^{1}}{\partial u^{1} / \partial x_{n}^{1}}=-\frac{\partial F / \partial e^{U}}{\partial F / \partial x_{n}}=\frac{\partial u^{2} / \partial e^{2}}{\partial u^{2} / \partial x_{n}^{2}} \text {. }
$$

Comparing (33) to condition (30) confirms our former remark that in the pure warm glow case emissions can be viewed as market commodities, since the same optimality conditions hold for them. A household can obtain a warm glow only by its own contributions to emission reduction, i. e. by its own hoarding of TEPs, free riding is not possible.

From these considerations it becomes clear that even if the pessimists with respect to free riding and the tragedy of the commons are right there remains still an important argument for involving households in emission trading as long as the existence of impurely altruistic preferences can be assumed. In this case emissions can be viewed as market commodities. If they are also traded like market commodities, i. e. as TEPs in a respective market with household participation, it is even possible to realize a Pareto optimum according to the adjusted Pareto condition (33). Only if households care neither for the world climate nor for warm glow feelings a total neglect of household preferences with respect to emission can yield a Pareto optimum, too, since in this case optimality conditions (32) or (33) vanish completely. But if households do not care at all for $\mathrm{CO}_{2}$ emissions there is no reason for an emission reduction policy in an anthropocentric world.

Figures 4 to 6 illustrate that under our assumptions with respect to the use of the revenues from the TEP sales, especially, in the pure warm glow case a switch of environmental policy from auctioning or grandfathering to a TEP system with household participation will lead to an increase in the utility level of impurely altruistic households, while the utility of all other households (for which $\partial \mathrm{u}^{\mathrm{h}} / \partial \mathrm{z}=0$ and/or $\partial \mathrm{z} / \partial \mathrm{e}^{\mathrm{h}}=0$ ) remains unchanged. This confirms that in this case such a policy change may lead to a Pareto superior situation for the economy under consideration.

It should be mentioned at this point that, of course, the same efficiency properties could also be attained by a TEP system where the TEPs are initially allocated to the public sector or the private production sector as long as households are enabled to participate in the TEP trade, i. e. as long they may buy and withdraw some of the TEPs from the quota available to polluters. The main reason to allocate the total TEP endowment initially to the household sector is an ethical one: such an allocation makes allowance for the fact that the natural environment should be part of the wealth of private households and that the property right to the environment should, therefore, be allocated to them.

\section{Concluding remarks}

The main disadvantage of traditional models of tradable emission permit regimes is that households have no possibilities to influence the determination of emission limits. These limits are fixed by governments as a result of a political process from which citizens usually are excluded. This is especially true for countries where there is no constitutional right to hold 
referenda with respect to single policy issues. Emission targets are often fixed as the result of international negotiations between the governments of several countries or groups of countries as was the case e. g. at the Climate Change Summit in Kyoto in 1997. Within the framework of a TEP system as proposed here the national population of a country would have the possibility to improve on the results of such international negotiations even after the national emission targets have been fixed. Of course, as was shown above, this influence of citizens after the determination of an "official" emission target is restrained to a reduction of the respective target values while a relaxation is not feasible.

Nevertheless, the good news is that under a TEP regime as proposed here households are able to exert some influence on environmental policy. This seems to be an important improvement in comparison to the traditional TEP models. It was demonstrated that a TEP system with household participation has the same cost efficiency properties as traditional TEP systems and that its ecological efficiency is in most cases higher (whenever at least some of the TEPs are withheld by households). It could even be shown that under fairly realistic assumptions (impure altruism instead of "true" preferences for the global $\mathrm{CO}_{2}$ emissions level) a switch from traditional TEP systems to emissions trading with household participation might lead to a Pareto improvement and even to a Pareto optimum.

It was also emphasized that, apart from such efficiency deliberations, there are important ethical reasons for a household participation in the fixing of emission limits. A TEP system as proposed here would imply a reallocation of the property right to nature to where it belongs, i. e. to the private households. This conforms with the early ideas of economic freedom and the principles of consumer sovereignty. These ethical considerations are the main reason for our proposition to allocate the total TEP endowment of the economy initially to the household sector. The efficiency properties of our TEP system could, however, also be attained by a TEP system where the initial endowment is allocated to the public sector or to the firms as long as households have the possibility to buy TEPs in order to reduce the global emissions level.

The fact that households actually have to pay for the environmental improvements they demand makes such a modified TEP system superior to the determination of emission limits by opinion polls or non-committal referenda. The decision to sacrifice some part of one's personal consumption for an environmental improvement is much more serious than the statement of a more or less arbitrary number in an opinion poll, which has no personal consequences at all. The typical validity and reliability problems which are well-known e.g. from contingent valuation surveys with respect to environmental improvements do not occur with a TEP system as proposed here: The determination of pollution limits by means of such a TEP system seems, therefore, to be much more reliable than by hypothetical valuation surveys or opinion polls. In this context it does not matter if the true motive for the storing decision is real concern for the environment or the longing for a "warm glow".

Last but not least, it should be mentioned that the initial distribution of emission permits to households can, of course, be used as an instrument of redistribution policy, i. e. as a means to improve distributional justice. The elaboration of a satisfactory method for the initial allocation of the emission permits is definitely one of the most important and most difficult tasks for the practical implementation of such a TEP regime. 


\section{References}

Andreoni, J. (1989), Giving with impure altruism: Applications to charity and ricardian equivalence, Journal of Political Economy 97, 1447-1458.

Andreoni, J. (1990), Impure altruism and donations to public goods: A theory of warm-glowgiving, The Economic Journal 100, 464-477.

Andreoni, J. (1995), Co-operation in public good experiments: Kindness or confusion?, American Economic Review 85, 891-904.

Baumol, W. J. / Oates, W. E. (1971), The use of standards and prices for the protection of the environment, Swedish Journal of Economics 73, 42-54.

Bohm, P. (1972), Estimating demand for public goods, European Economic Review 3, 111130.

Cramton, P. / Kerr, S. (1998), Tradable carbon permit auctions. How and why to auction not grandfather, University of Maryland, Working Paper published in WWW (http://netec.mcc.ac.uk/WoPEc/data/Papers/pccpccumd98wpTC.html).

Cramton, P. / Kerr, S. (1999), The Distributional Effects of Carbon Regulation, in: Sterner, T. (ed.), The Market and the Environment, Edward Elgar, Cheltenham, 255-271.

Cummings, R. / Harrison, G. / Rutström, E. (1995), Homegrown values and hypothetical surveys: Is the dichotomous choice approach incentive compatible?, American Economic Review 85, 260-66.

Hardin, G. (1968), The Tragedy of the Commons, Science 162, 1243-1248.

Harrison, D. (1999), Tradable permits for air pollution control: the US experience, in: OECD, Implementing domestic tradable permits for environmental protection, Proceedings of the conference "Domestic Tradable Permit Systems for Environmental Protection: Issues and Challenges; 1998, Paris

Hutt, W. H. (1936 / 1990), Economists and the Public - A Study of Competition and Opinion, New Brunswick and London 1990.

Hutt, W. H. (1943), Plan for reconstruction - A project for victory in war and peace, London.

Johnstone, N. (1999), Permit allocation methods, greenhouse gases, and competitiveness, OECD Working Papers 7 (98), Paris.

Madariaga, B. / McConnell, K. E. (1987), Exploring Existence Value, Water Resources Research 23, 5, 936-942.

Schmalensee, R. / Joskow, P. L. / Ellerman, A. D. / Montero, J.-P. / Bailey, E. M. (1998), An interim evaluation of sulfur dioxide emissions trading, Journal of Economic Perspectives 12 (3), 53-68.

Portney, P. R. (1994), The contingent valuation debate: Why economists should care, Journal of Economic Perspectives 8, 3-17.

Schneider, F. / Pommerehne, W. W. (1981), Free riding and collective action: An experiment in public microeconomics, Quarterly Journal of Economics 97, 689-702.

Schneider, F. / Wagner, A. F. (1998), Emission trading and environmental taxes as efficient flexible instruments for European climate policy: Remarks from an economist's perspective, Research Paper. 
Tietenberg, T. (1998a), Tradable Permits and the Control of Air Pollution - Lessons from the United States, in: Bonus, H. (ed.), Umweltzertifikate, Zeitschrift für angewandte Umweltforschung, Sonderheft 9, 11-32.

Tietenberg, T. (1998b), Ethical influences on the evolution of the US tradable permit approach to air pollution control, Ecological Economics 24 (2), 241-257. 